\title{
Sugarcane cell suspension reveals major metabolic changes under different nitrogen starvation regimes
}

\author{
Alexandra Bottcher ${ }^{1}$ (D), Adilson Pereira Domingues-Junior ${ }^{2,3}$ (D), Leonardo Perez de Souza² (D), \\ Takayuki Tohge² (D), Wagner Luiz Araújo (D), Alisdair Robert Fernie² (D), Paulo Mazzafera ${ }^{1,3, \star}$ (D) \\ 1. Universidade Estadual de Campinas - Instituto de Biologia - Departamento de Biologia Vegetal - Campinas (SP), Brazil. \\ 2. Max-Planck-Institut für Molekulare Pflanzenphysiologie-Potsdam-Golm, Germany. \\ 3. Universidade de São Paulo - Escola Superior de Agricultura "Luiz de Queiroz" - Laboratório de Produção Vegetal - Piracicaba (SP), Brazil. \\ 4. Universidade Federal de Viçosa - Departamento de Biologia Vegetal - Viçosa (MG), Brazil. \\ Received: Jan. 10, 2021 | Accepted: Mar. 10, 2021 \\ Section Editor: Rafael Vasconcelos Ribeiro \\ *Corresponding author: pmazza@unicamp.br \\ How to cite: Bottcher, A., Domingues-Junior, A. P., Souza, L. P., Tohge, T., Araújo, W. L., Fernie, A. R. and Mazzafera, P. (2021). Sugarcane \\ cell suspension reveals major metabolic changes under different nitrogen starvation regimes. Bragantia, 80, e2921. https://doi. \\ org/10.1590/1678-4499.2021-0009
}

\begin{abstract}
Cell suspension culture has been used as a model to study metabolic changes to several stresses. To have detailed information of nitrogen ( $\mathrm{N}$ ) limitation on sugarcane metabolism, a controlled study of the primary metabolites and representative compounds of secondary metabolism was developed using suspension cells growing under three different $\mathrm{N}$ regimes: normal condition $\left(40 \mathrm{mmol} \cdot \mathrm{L}^{-1} \mathrm{NO}_{3}^{-}\right)$, slightly deficient $\left(12 \mathrm{mmol} \cdot \mathrm{L}^{-1} \mathrm{NO}_{3}^{-}\right)$and completely deficient $\left(0 \mathrm{mmol} \cdot \mathrm{L}^{-1} \mathrm{NO}_{3}^{-}\right)$. Sugarcane cells were harvested after 3 and 7 days of treatment. $\mathrm{A}$ range of changes in the levels of amino acids, organic acids, sugars and phenolic compounds were observed upon the growth conditions applied. Nitrogen limitation remarkably affected the amino acids and carbohydrates biosynthesis, which, associated with the changes observed on phenolic compounds contents, indicates the upregulation of carbon sink compensation mechanisms in these sugarcane cells exposed to $\mathrm{N}$ starvation. As expected, the results showed that $\mathrm{N}$ limitation might cause an extensive metabolic reprogramming of both carbon and $\mathrm{N}$ metabolism in sugarcane cells, and these changes are related to the intensity of the starvation. Nitrogen is essential for plant growth and development, and its limitation sharply reduces crop yield. Thus, these results open new perspectives for in planta studies concerning carbon and $\mathrm{N}$ metabolisms balance in this crop.
\end{abstract}

Key words: amino acids, growth, primary metabolism, secondary metabolism, sugarcane yield.

\section{INTRODUCTION}

Fertilization with nitrate, the main form of nitrogen (N) uptake by plants, results in higher levels of $\mathrm{N}$ compounds, increase growth and lead to profound alterations in carbon metabolism (Lea and Miflin 2018; Stitt 1999). Nitrate is absorbed from soil solution via specific membrane transporters, being reduced to ammonium by following activities of nitrate reductase (NR) and nitrite reductase (NiR) enzymes. The ammonium produced is incorporated into amino acids by the actions of glutamine synthetase (Peng et al. 2007) and glutamate synthase (GOGAT) (Guo et al. 2007; Lea and Miflin 2018). Organic acids metabolism is essential for the assimilation of nitrate because while the 2-oxoglutarate is responsible for accepting the ammonium in GOGAT pathway, both malate and fumarate act as counter-anions and prevent alkalization during nitrate assimilation (Stitt 1999). Therefore, the adaptation to $\mathrm{N}$ limitation requires physiological and biochemical changes. These include increments in the capacity to acquire $\mathrm{N}$, reduction in both photosynthesis and growth, remobilization of $\mathrm{N}$ from mature to immature organs, and stimulation of phenolics biosynthesis to reduce oxidative damages, which is also associated with N starvation (Diaz et al. 2006; Peng et al. 2007). 
Sugarcane (Saccharum spp.) is an important crop for renewable bioenergy and is frequently affected by $\mathrm{N}$ deficiency stress (Salvato et al. 2019; Bassi et al. 2018). To achieve rapid initial growth of ratoons and substantial biomass accumulation, sugarcane requires considerable quantities of $\mathrm{N}$ fertilizers, such as $175 \mathrm{~kg}$ of N$\cdot \mathrm{ha}^{-1}$ (Portz et al. 2012). Besides the importance of sugarcane for first and, more recently, second bioethanol generation (Byrt et al. 2011; Dias et al. 2012, Llerena et al. 2019), there is still a considerable lack of information about $\mathrm{N}$ use efficiency in this crop. Relevant progress has been provided by breeding programs for a better understanding of the physiological, biochemical and molecular responses of plants under $\mathrm{N}$ starvation, and most knowledge obtained has been focused in practical field aspects (Abreu et al. 2020; Calderan-Rodrigues et al. 2021). The $\mathrm{N}$ cycle in sugarcane is sophisticated and hugely influenced by environmental conditions, such as soil temperature and humidity (Bassi et al. 2018; Salvato et al. 2019). Besides, it is altered according to N supply, as fertilizer, inputs and losses from decomposition and its transformation in soil by microbial activity (Thorburn et al. 2005).

To date, there have been few reports about changes in metabolites levels in sugarcane, under $\mathrm{N}$ deficiency. Therefore, this study investigates the response of sugarcane suspension cell cultures to $\mathrm{N}$ deficiency due to their advantage to perform essays under controlled conditions (Ferreira et al. 2018). Cell suspension has been used as a powerful technique to understand plant metabolism, broadening further approaches to be carried out in planta (Abd El-Kader et al. 2019). In this way, a moderate and strong deficiency of $\mathrm{N}$ was imposed, adding only 30 and $0 \%$ of nitrate in basal medium. A wide range of metabolites was analyzed using gas and liquid chromatography-mass spectrometry (GC and LC-MS). The identification of such responsive metabolites is expected to be helpful to unveil mechanisms of stress tolerance and serve as a guide for future in planta studies, including breeding programs, to produce improved sugarcane genotypes to face different conditions of $\mathrm{N}$ deficiency in the field.

\section{MATERIAL AND METHODS}

\section{Cell cultures and stress treatments}

Cell cultures of sugarcane variety IACSP96-2008 were induced and maintained according to Cesarino et al. (2013). Variety IACSP96-2008 has been used in the sugarcane breeding program of Instituto Agronômico de Campinas because of its genetic stability, adaptability and productivity (Landell et al. 2005). Nitrogen stress was imposed by transferring cells to media with 12 (30\%) or $0 \mathrm{mmol} \cdot \mathrm{L}^{-1}(0 \%)$ of nitrate (NO-3) in MS (Murashige and Skoog 1962) supplemented with vitamins (M519, PhytoTechnology, USA), 3\% (w/v) sucrose, $3 \mathrm{mg} \cdot \mathrm{L}^{-1}$ 2,4-dichlorophenoxiacetic acid (2,4-D). Preliminary tests showed that $30 \% \mathrm{NO}_{3}^{-}$could still support cell growth during the period we carried out the experiment. The $30 \% \mathrm{~N}$ media contained $30 \%$ of $\mathrm{KNO}_{3}$ and $\mathrm{NH}_{4} \mathrm{NO}_{3}$, with all other components at correct concentrations as the full media; the $0 \% \mathrm{~N}$ medium had no addition of $\mathrm{NH}_{4} \mathrm{NO}_{3}$ and $\mathrm{KNO}_{3}$, which were replaced by $\mathrm{KCl}$ to keep $\mathrm{K}$ concentration. Cells were harvested 3 and 7 days after treatment (DAT).

\section{Cell viability}

Cell viability was assessed by adding $2 \mu \mathrm{L}$ of fluorescein diacetate $\left(1 \mathrm{mg} \cdot \mathrm{mL}^{-1}\right)$ in $1 \mathrm{~mL}$ medium containing cells and then incubated for $15 \mathrm{~min}$ at $37^{\circ} \mathrm{C}$. Fluorescence was detected at $530 \mathrm{~nm}$, with excitation at $488 \mathrm{~nm}$ (Coder 2001).

\section{Primary and secondary metabolites profiling}

Extraction and analysis of primary metabolites by GC-MS followed the protocol described by Lisec et al. (2006). For secondary metabolites, extraction and analysis by LC-MS were performed according to Tohge and Fernie (2010) with minor changes. Briefly, in the extraction step, $20 \mathrm{mg}$ of lyophilized sugarcane cells were extracted with $80 \%$ methanol in distilled water. The mixture was homogenized for $3 \mathrm{~min}$ at $25 \mathrm{~L} \cdot \mathrm{s}^{-1}$. After two consecutive centrifugations (15,000 xg, $\left.10 \mathrm{~min}\right)$, the supernatant was recovered $(300 \mu \mathrm{L})$ and used for LC-MS analysis. The LC-MS system, methodology and quantification were done as described by Tohge and Fernie (2010). The main metabolites detected are listed in the Table 1. 
Table 1. Abbreviations of the major compounds identified in leaves and stems of Eucalyptus globulus and Eucalyptus grandis.

\begin{tabular}{|c|c|}
\hline Abbreviation & Compound \\
\hline Ala & Alanine \\
\hline ApCag & Apigenin-C-arabinoside-glucoside \\
\hline ApCar & Apigenin-C-arabinoside-rhamnoside \\
\hline $\mathrm{ApCg}$ & Apigenin-C-glucoside \\
\hline Asn & Asparagine \\
\hline Asp & Aspartate \\
\hline b-Ala & $\beta$-Alanine \\
\hline CQA & Caffeoylquinic acid \\
\hline CSA & Caffeoylshikimic acid \\
\hline DHA & Dehydroascorbic acid \\
\hline FQA & Feruloylquinic acid \\
\hline GABA & Gamma-aminobutyric acid \\
\hline Glu & Glutamate \\
\hline Gly & Glycine \\
\hline lle & Isoleucine \\
\hline LtCag & Luteolin-C-arabinoside-glucoside \\
\hline Met & Methionine \\
\hline MCoumQA & Methoxycoumaroyl-quinate \\
\hline Orn & Ornithine \\
\hline p-CoumQA & $p$-Coumaroyl-quinate \\
\hline Phe & Phenylalanine \\
\hline Pro & Proline \\
\hline Put & Putrescine \\
\hline Ser & Serine \\
\hline TrOrg & Tricin-O-rhamnoside-glucoside \\
\hline Tyr & Tyrosine \\
\hline Val & Valine \\
\hline
\end{tabular}

\section{Statistical analysis}

Data were statistically examined through analysis of variance and tested for significance $(\mathrm{p}<0.05)$ using student's t-test. Pearson correlation test was used to evaluate the relation among different metabolites analyzed. All the statistical analyses were performed using the software GraphPad Prism 5.00 for Windows (GraphPad Software, San Diego, CA, USA). Principal component analysis (PCA) was performed using R software version 2.12.2. (http://www.r-project.org), according to Ruprecht et al. (2011).

\section{RESULTS}

\section{Cell viability}

The viability of cells was confirmed 7 DAT in all treatments. The absorption and retention of free fluorescein indicated that all treatments had viable cells at the harvesting time (Fig. 1). 

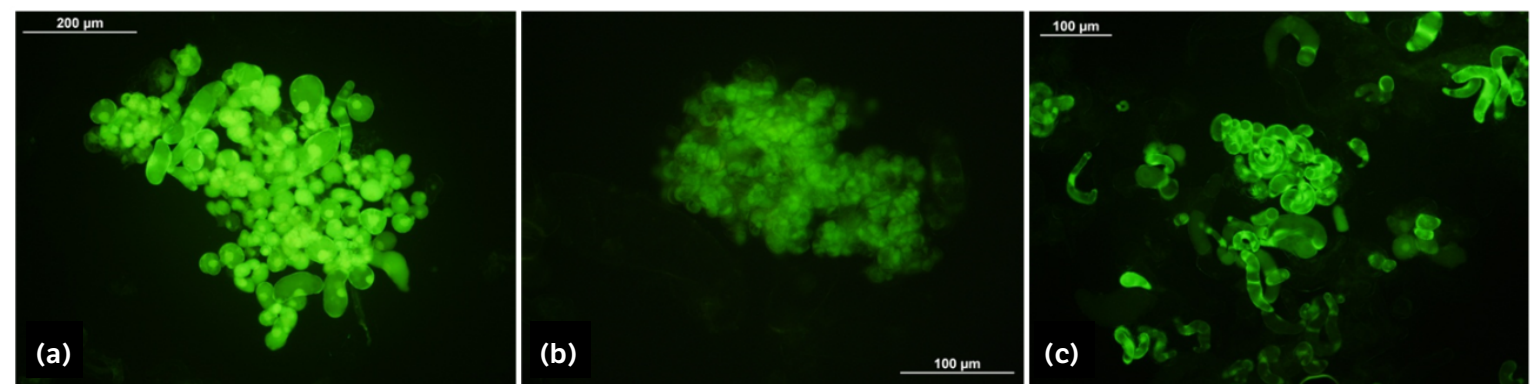

Figure 1. Seven-days-old sugarcane cells stained with fluorescein diacetate (FDA).

Note. Intense green fluorescence indicates physiologically live cells and intact cell wall. (a) Control cells; (b) $30 \% \mathrm{~N}$ and (c) $0 \% \mathrm{~N}$.

Nitrogen limitation stresses lead to extensive reprogramming of metabolites in sugarcane cells.

In response to the imposed $\mathrm{N}$ treatments, considerable changes in levels of a wide range of different amino acids (Fig. 2), organic acids (Fig. 3), sugar (Fig. 4), sugar alcohols and $\mathrm{N}$ compound (Fig. 5) and phenolic compounds (Fig. 6) were evident.

More specifically, there were notable changes in the contents of some amino acids (Fig. 2), namely, asparagine (Asp), glutamic acid (Glu), isoleucine (Ile), phenylalanine (Phe) (30\% N, 3 DAT), methionine (Met) and tyrosine (Tyr) (0\% N, 7 DAT) were all significantly increased compared to the control group. Meanwhile, asparagine (Asn), $\beta$-alanine ( $\beta$-Ala), Glu ( $0 \% \mathrm{~N}, 3$ DAT) and Asn and Asp (30\% N, 7 DAT) had their levels reduced compared to the same group. Time-related changes on amino acids levels were also observed, levels of Asp, Glu, ornithine (Orn) and Tyr showed a reduction between 3 and 7 DAT for cells exposed to $30 \% \mathrm{~N}$, while the treatment $0 \% \mathrm{~N}$ promoted an increase of Asp, $\beta$-Ala and Glu contents during the same timeframe.

(a)

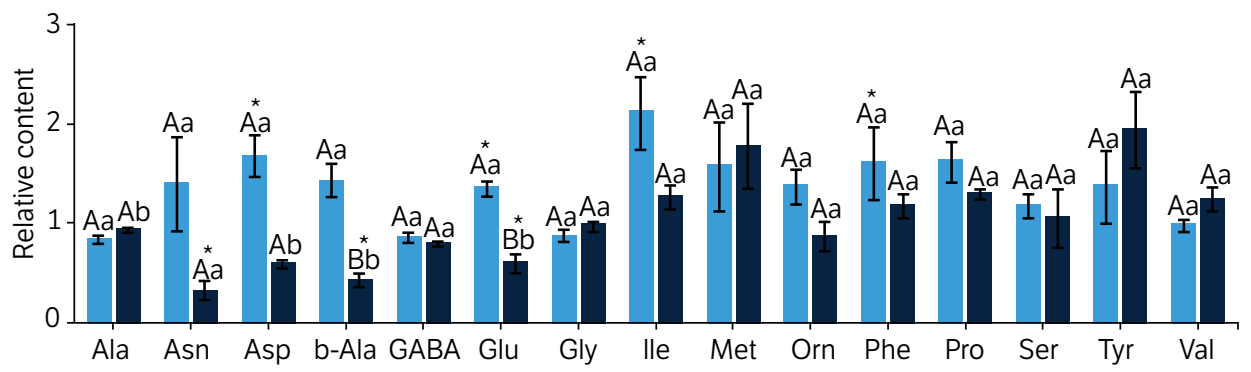

(b)

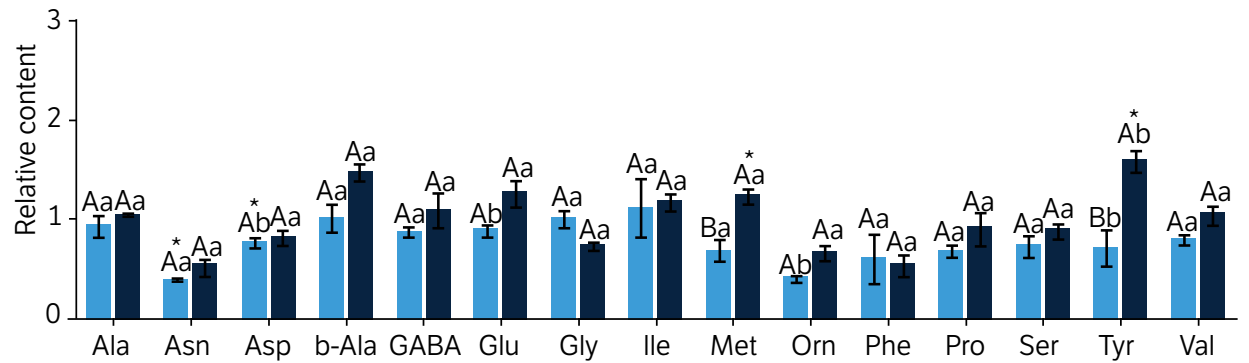

$30 \% \mathrm{~N}$

- $0 \% \mathrm{~N}$

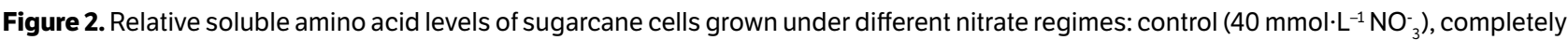
deficient $(0 \% \mathrm{~N})$ and slightly deficient $(30 \% \mathrm{~N})$.

Note. Cells harvested after (a) 3 and (b) 7 days after the beginning of treatments. Data were normalized concerning the mean response calculated for control groups. Different capital letters indicate a statistical difference between nitrogen deficiency treatments at the same harvesting day; different small letters indicate a statistical difference between harvesting days at the same $\mathrm{N}$ deficiency treatment, and asterisks indicate significant difference compared to control groups. Values are mean $\pm \operatorname{SE}(n=3)$.

Nitrogen starvation also promoted changes over the levels of some organic acids (Fig. 3). Tricarboxylic acid (TCA) cycle intermediates fumarate and malate showed increased levels in cells growing at 30\% N (3 DAT) and reduced amount in cells growing at $0 \% \mathrm{~N}(3 \mathrm{DAT})$. Glycerate and malate also presented the same pattern observed for TCA cycles intermediates in cells growing at 30 and $0 \% \mathrm{~N}$ and harvested 3 days after the beginning of treatments (Fig. 3a). With 7 DAT (Fig. 2b), only glycerate, 
malate and nicotinate continued presenting changes compared to the control group. Glycerate and nicotinate had decreased levels in cells growing at $30 \% \mathrm{~N}$ and malate increased its content for $0 \%$ treatment. Complementarily, glycerate content had the most profound change, with a drastic drop between 3 and 7 DAT in cells growing at $30 \% \mathrm{~N}$ and the opposite occurring in cells growing at complete $\mathrm{N}$ deficiency.

(a)

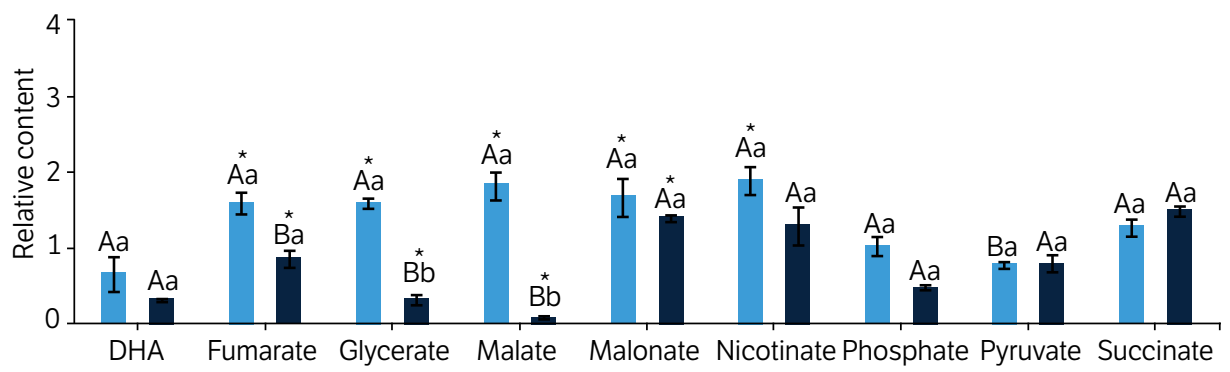

(b)

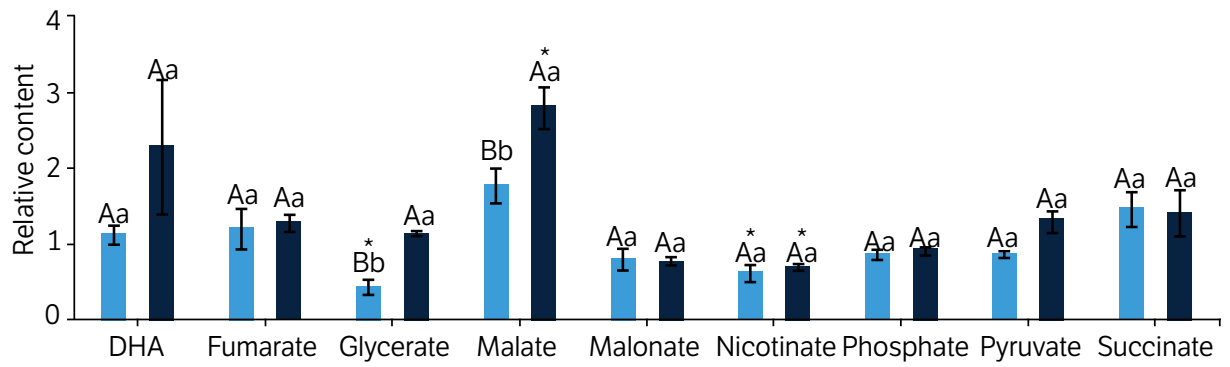

DHA Fumarate Glycerate Malate Malonate Nicotinate Phosphate Pyruvate Succinate

Figure 3. Relative organic acids levels of sugarcane cells grown under different nitrate regimes: control $\left(40 \mathrm{mmol} \cdot \mathrm{L}^{-1} \mathrm{NO}_{3}^{-}\right)$, completely deficient $(0 \% \mathrm{~N})$ and slightly deficient $(30 \% \mathrm{~N})$.

Note. Cells harvested after (a) 3 and (b) 7 days after the beginning of treatments. Data were normalized concerning the mean response calculated for control groups. Different capital letters indicate a statistical difference between nitrogen deficiency treatments at the same harvesting day; different small letters indicate a statistical difference between harvesting days at the same $\mathrm{N}$ deficiency treatment, and asterisks indicate significant difference compared to control groups. Values are means \pm SE $(n=3)$.

(a)

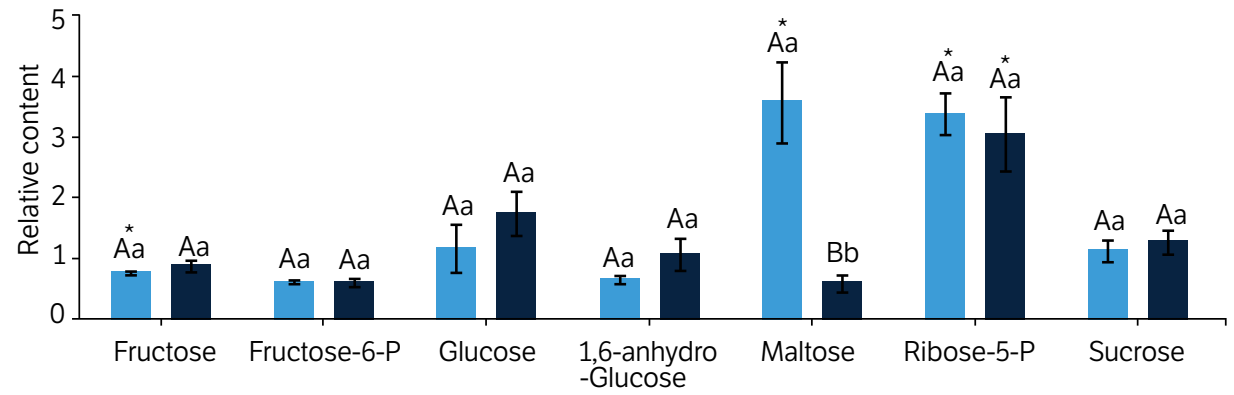

(b)

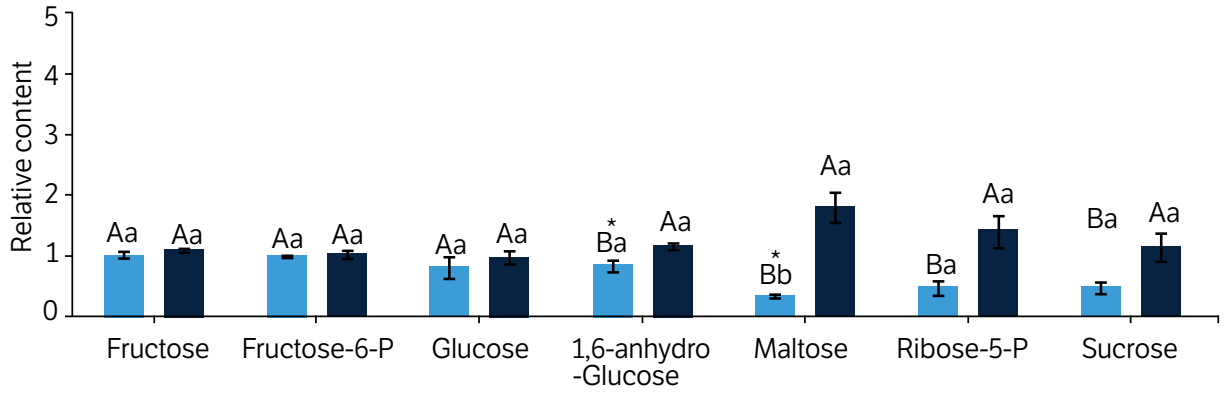

Figure 4. Relative carbohydrate levels of sugarcane cells grown under different nitrate regimes: control $\left(40 \mathrm{mmol} \cdot \mathrm{L}^{-1} \mathrm{NO}_{3}^{-}\right)$, completely deficient $(0 \% \mathrm{~N})$ and slightly deficient $(30 \% \mathrm{~N})$.

Note. Cells harvested after (a) 3 and (b) 7 days after the beginning of treatments. Data were normalized concerning the mean response calculated for control groups. Different capital letters indicate a statistical difference between nitrogen deficiency treatments at the same harvesting day; different small letters indicate a statistical difference between harvesting days at the same $\mathrm{N}$ deficiency treatment, and asterisks indicate significant difference compared to control groups. Values are means $\pm \operatorname{SE}(n=3)$. 
Few carbohydrates responded to the imposed $\mathrm{N}$ deficiency treatments. While fructose showed a slight decrease in the $30 \%$ $\mathrm{N}$ treatment at $3 \mathrm{DAT}$, maltose and ribose-5-phosphate levels increased at the same treatment and harvest day. For 7 DAT, only 1,6-anhydro-glucose and maltose had reduced amount in the 30\% $\mathrm{N}$ group compared to the control. Sucrose and glucose did not present any alteration under the imposed treatments (Fig. 4), and maltose was the carbohydrate with the most profound change in their levels among the treatments, with a reduction between 3 and $7 \mathrm{DAT}$ at $30 \% \mathrm{~N}$ treatment and an increase at $0 \% \mathrm{~N}$.

Among the sugar alcohols identified in this work, glycerol and glycerol-3-phosphate had increased levels in cells growing at $30 \% \mathrm{~N}$ compared to the control group (3 DAT), and only glycerol continued to show altered levels in $30 \% \mathrm{~N}$ treatment at 7 DAT (Fig. 5).
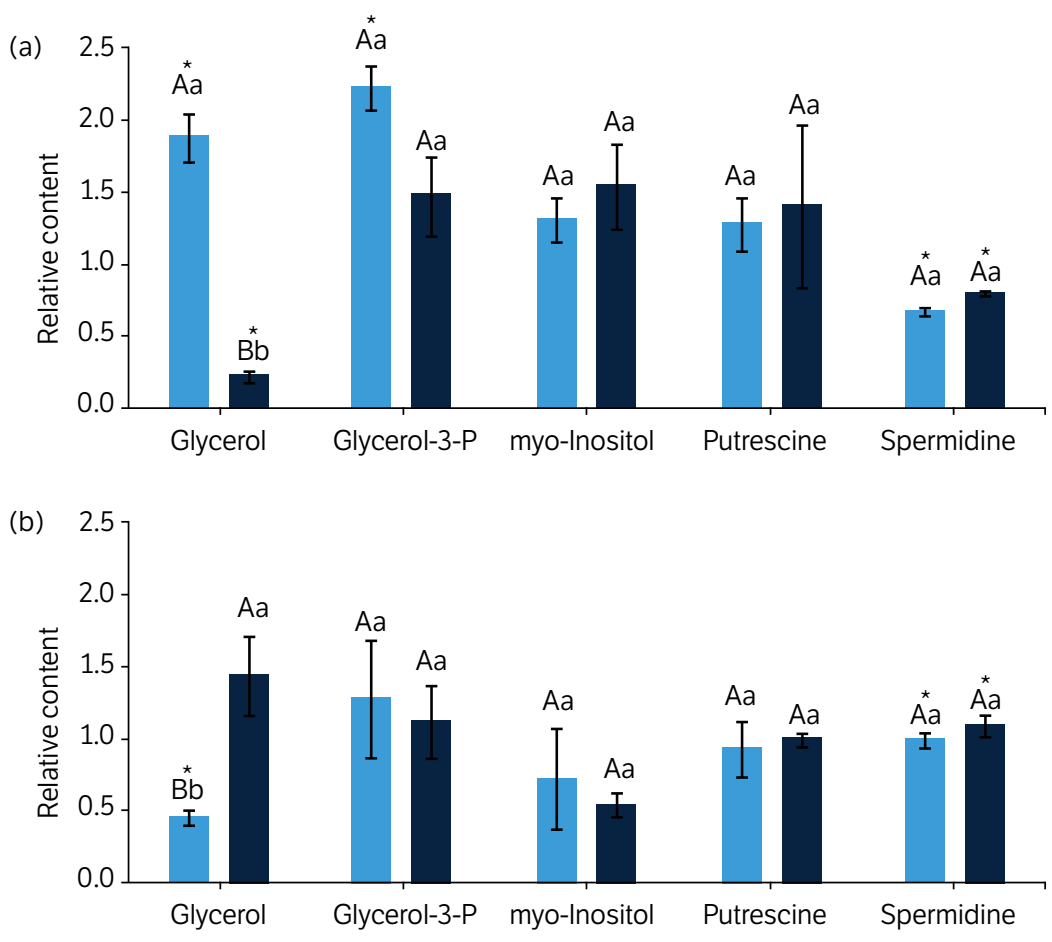

Figure 5. Relative alcohol sugars and $\mathrm{N}$ compounds levels of sugarcane cells grown under different nitrate regimes: $\operatorname{control}\left(40 \mathrm{mmol} \cdot \mathrm{L}^{-1} \mathrm{NO}_{3}^{-}\right)$, completely deficient $(0 \% \mathrm{~N})$ and slightly deficient $(30 \% \mathrm{~N})$.

Note. Cells harvested after (a) 3 and (b) 7 days after the beginning of treatments. Data were normalized concerning the mean response calculated for control groups. Different capital letters indicate a statistical difference between nitrogen deficiency treatments at the same harvesting day; different small letters indicate a statistical difference between harvesting days at the same $\mathrm{N}$ deficiency treatment, and asterisks indicate significant difference compared to control groups. Values are means \pm SE $(n=3)$.

Concerning the secondary metabolites, it was possible to identify 11 compounds related to the phenylpropanoid pathway. Cells growing in the complete absence of $\mathrm{N}$ showed the most profound changes in the levels of these compounds, particularly for p-coumaroylquinic and shikimic acids ( $p$ CoumQA and CSA, respectively), whose content significantly increased at 3 DAT and immediately dropped at 7 DAT (Fig. 6). Flavonoids compounds, such as apigenin, lutein and tricin derivates, also responded to $\mathrm{N}$ starvation at 3 and 7 DAT, mainly by increasing their levels when exposed to the most severe $\mathrm{N}$ deficiency treatment. Additionally, CSA, p-coumaroyl-quinate, apigenin$\mathrm{C}$-arabinoside-rhamnoside, and tricin-O-rhamnoside-glucoside showed a remarkable drop in their contents between 3 and 7 DAT in both treatments.

Principal component analysis (Fig. 7a) and a correlation matrix evaluation (Fig. 7b) were carried out to identify the most responsive primary metabolites to the $\mathrm{N}$ starvation conditions applied at this work. The first two principal components (PCs) separated the samples into clusters somewhat well-defined, determining a clear difference in metabolite composition between each treatment. Sugars levels at 7 DAT and organic acids contents at 3 DAT are the main responsible for separation along PC1 (Table 2), separating N starvation cells from those grown at ideal conditions (control group). 

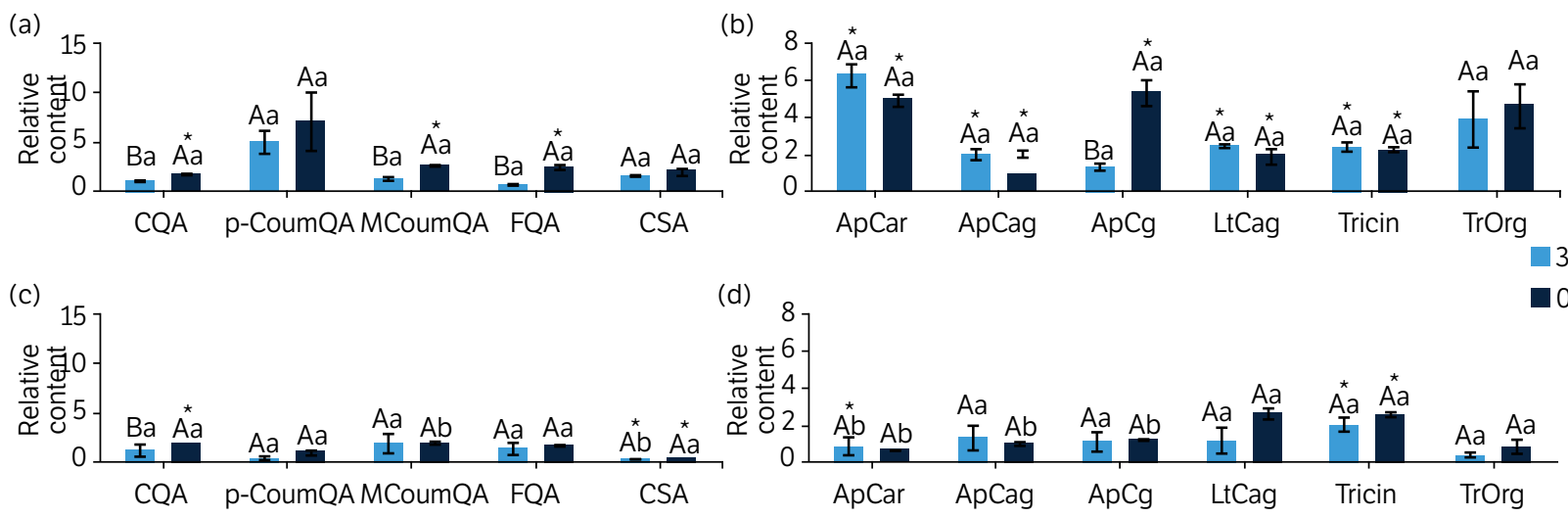

Figure 6. Relative ( $a$ and $c$ ) phenylpropanoid and ( $b$ and $d$ ) flavonoids levels of sugarcane cells grown under different nitrate regimes: control $\left(40 \mathrm{mmol} \cdot \mathrm{L}^{-1} \mathrm{NO}_{3}^{-}\right)$, completely deficient $(0 \% \mathrm{~N})$ and slightly deficient $(30 \% \mathrm{~N})$.

Note. Cells harvested after ( $a$ and $b$ ) 3 and ( $b$ and d) 7 days after the beginning of treatments. Data were normalized concerning the mean response calculated for control groups. Different capital letters indicate a statistical difference between nitrogen deficiency treatments at the same harvesting day; different small letters indicate a statistical difference between harvesting days at the same $\mathrm{N}$ deficiency treatment, and asterisks indicate significant difference compared to control groups. Values are means $\pm \operatorname{SE}(n=3)$.
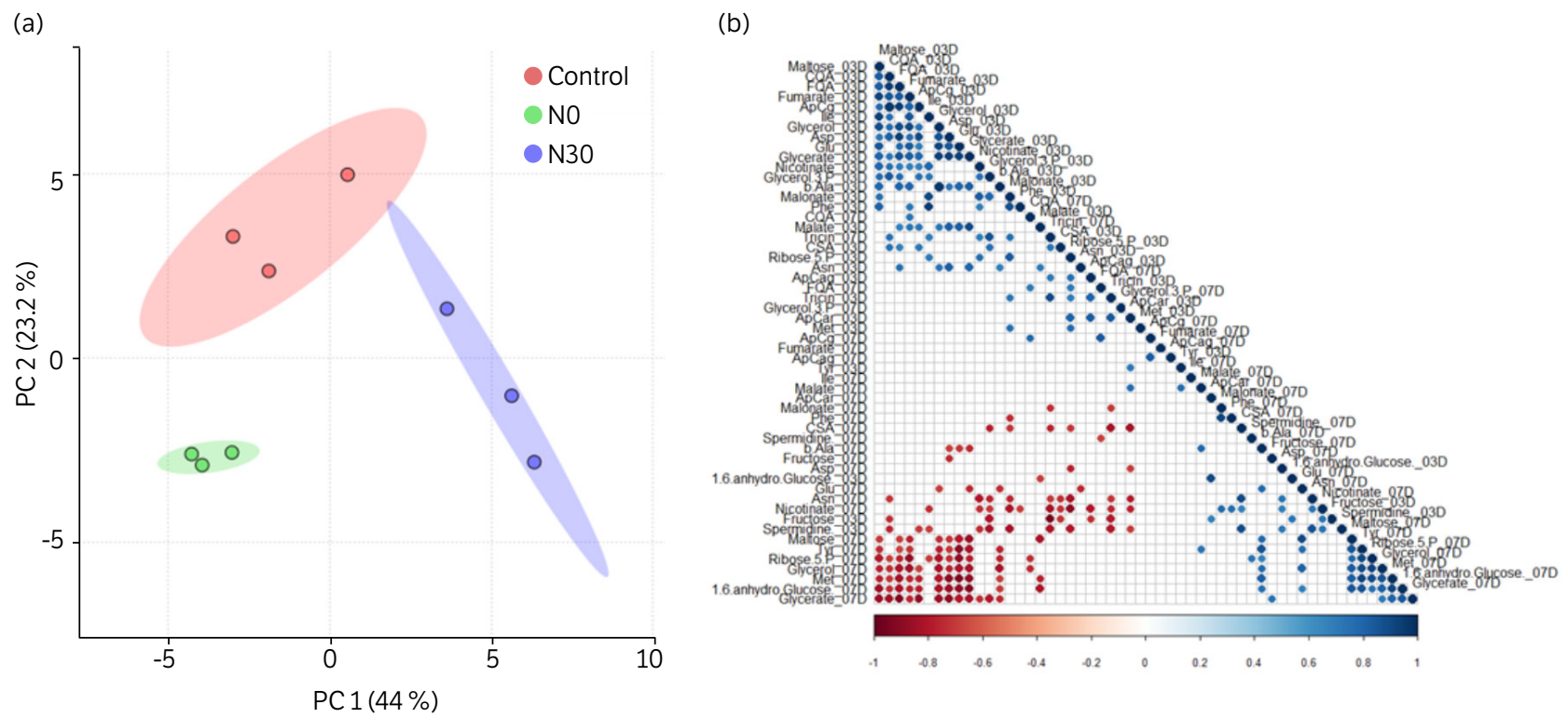

Figure 7. (a) Principal component analysis (PCA) of metabolites identified in sugarcane cells growing at different nitrogen deficiency regimes. Different treatments are marked with distinct dots: red, control ( $\left.40 \mathrm{mmol} \cdot \mathrm{L}^{-1} \mathrm{NO}_{3}^{-}\right)$; blue slightly $\mathrm{N}$ deficient $(30 \% \mathrm{~N})$ and green severe $\mathrm{N}$ deficient $(0 \% \mathrm{~N})$. (b) Correlation matrix of primary and secondary metabolites identified in sugarcane cells growing at different nitrogen deficiency regimes.

Note. Only metabolites showing statistical difference among treatments are represented in this matrix. Correlations represented with $p$-value $<0.05$.

Table 2. Main vectors of the first two principal components (PC) of the analysis presented in Fig. 6 .

\begin{tabular}{ccc}
\hline Quadrants of PCA analysis & First PC & Second PC \\
\hline \multirow{3}{*}{ Positive portion } & Maltose_03DAT & Phenylalanine_07DAT \\
\cline { 2 - 3 } & Fumarate_03DAT & Malonate_07DAT \\
\cline { 2 - 3 } & Glycerol_03DAT & Nicotinate_07DAT \\
\cline { 2 - 3 } & Glutamate_03DAT & Spermidine_03DAT \\
\hline \multirow{3}{*}{ Negative portion } & Glycerate_03DAT & Asparagine_07DAT \\
\cline { 2 - 3 } & 1,6-anhydro-Glucose_07DAT & Ribose-5-P_03DAT \\
\cline { 2 - 3 } & Methionine_07DAT & Malate_07DAT \\
\cline { 2 - 3 } & Glycerate_07DAT & Malonate_03DAT \\
\cline { 2 - 3 } & Ribose-5-P_07DAT & Methionine_03DAT \\
\cline { 2 - 3 } & Glycerol_07DAT & B-Alanine_07DAT \\
\hline
\end{tabular}




\section{DISCUSSION}

Nitrogen starvation is an important limitation of sugarcane productivity (Patade et al. 2012; Robinson et al. 2011). It is known that $\mathrm{N}$ deficiency causes changes in the metabolite profiles, with a reduction of amino acids and sugar contents and an upregulation of secondary metabolites biosynthesis (Schlüter et al. 2012). In this study, different amino acids seem to respond to moderate (Asp, Ile and Phe) or severe (Asn, $\beta$-Ala, Met and Tyr) N limitation, while others seem to be commonly involved in the response against both $\mathrm{N}$ deficiency (Glu; Fig. 2).

The soluble amino acids content is highly variable among plants cell types, species and physiological conditions, but the pattern of changes follow the same coordinate way (Bassi et al. 2018; Schachtman and Shin 2007). Those amino acids sharing the same biosynthetic pathway usually show a higher correlation (Fritz et al. 2006; Noctor et al. 2002; Schlüter et al. 2012); Gln, Glu, Asp and Asn serve as source and transport of N, as well they are closely linked to the balance of primary carbon metabolism and $\mathrm{N}$ assimilation (Galili et al. 2008; Noctor et al. 2002). In that way, these amino acids showed a similar response in sugarcane cells under N limitation; Asp, Asn and Glu responded with down accumulation under strong $\mathrm{N}$ deficiency once the low $\mathrm{N}$ availability in the media, which suggests a reduction of $\mathrm{N}$ assimilation activity even after a short time of treatment (3 DAT, Fig. 2a). Here, it is essential to highlight that this rapid shift of the concentration of the amino acids was probably related to the nature of the system tested. As the media was changed drastically and cells could not rely on $\mathrm{N}$ reserves, as in a healthy plant, the absence of a storage source would accelerate responses to the $\mathrm{N}$ starvation imposed here. Additionally, once cells survived until 7 DAT (Fig. 1), part of the amino acids should have been used to support this survival as precursors for structural biomolecules biosynthesis, such as proteins.

Amino acids as tryptophane (Trp), Met, Pro, Phe and arginine (Arg) are direct or indirectly precursors of secondary metabolites and hormones, being involved in the tolerance of plants against biotic and abiotic stresses (Galili et al. 2008; Soares et al. 2019). The amino acids Met, Phe and Pro were identified in this analysis (Fig. 2), and the content of the first one showed a significant increase under $\mathrm{N}$ deficiency treatments compared to the control group. The Phe content was up accumulated at 3 DAT in cell cultures growing at $30 \%$ of N. Proline (Pro), however, maintained unaltered content for both treatments, and possibly was not involved in the tolerance against the stresses applied in this work (Fig. 2a and 2b). This myriad of responses of amino acids levels when plants face $\mathrm{N}$ starvation is well characterized in the literature. While maize and tomato plants showed a reduction of amino acids content when exposed to $\mathrm{N}$ deficiency (i.e., Trp, Arg, Asp), different accessions of Arabidopsis had an increase of the levels of some amino acids (glycine - Gly, histidine - His, leucine - Leu, Ile). This response was explained as an ability for adjusting the amino acids to compensate the decrease of $\mathrm{N}$ availability, mainly through an increased protein degradation (Bassi et al. 2018; Fritz et al. 2006; Salvato et al. 2019).

Secondary metabolites biosynthesis, especially the phenylpropanoid pathway, represent one of the most important amino acids sinks in plants (Galili et al. 2008). In that way, similar to that observed by Bottcher et al. (2013) in sugarcane leaves and stems, most of the phenylpropanoids found in this work corresponded to O- and C-glycosylated flavonoids, especially those derived from apigenin, luteolin and tricine (Fig. $6 \mathrm{~b}$ and $6 \mathrm{~d}$ ). These phenolic compounds accumulated in sugarcane cells grow in media with $\mathrm{N}$ deficiency, and the same pattern was observed for shikimic and caffeoylquinic acids (Fig. 6a and 6c), which are important precursors of the lignin biosynthesis (Bassi et al. 2018; Fritz et al. 2006; Salvato et al. 2019). The mechanisms by which nitrogen controls phenolic metabolism are not fully understood, although some works have shown that it must be related to the balance between carbon and nitrogen metabolisms (Fritz et al. 2006; Salvato et al. 2019). In that case, the biosynthesis of phenolic compounds consumes high quantities of carbon skeleton and, under $\mathrm{N}$ deficiency scenario, it is postulated that plants will direct their metabolism to pathways related to C-rich metabolites (such as phenolic compounds), in an attempt to recover the balance between carbon and nitrogen availability and avoid photosynthesis inhibition promoted by such imbalance (Bassi et al. 2018; Fritz et al. 2006). Moreover, nitrate, the main form of $\mathrm{N}$ uptake by plants, seems to play a critical role, downregulating portions of phenylpropanoid metabolism (Bassi et al. 2018; Fritz et al. 2006; Salvato et al. 2019). Additionally, lignin biosynthesis also acts as an important carbon sink in plant metabolism (Wang and Dixon 2012; Zhong et al. 2010). In that sense, although lignin content and its monomers have not been measured here, shikimic and caffeoylquinic acids had a negative correlation with phenylalanine and tyrosine content in cells harvested 
after seven days of $\mathrm{N}$ deficiency $(\mathrm{R}=-1$, at $\mathrm{p}$-value $<0.05$, Fig. $7 \mathrm{~b})$. Here, it is important to highlight that phenylalanine is the precursor of most phenolic compounds, including lignin, and any disturbance on downstream biosynthetic pathways may also affect aromatic amino acids balance (Bassi et al. 2018; Wang and Dixon 2012; Zhong et al. 2010).

Organic acids are involved in numerous functions in plant cell metabolism, and changes in their amount are variable among species, developmental stages and tissue types (Araújo et al. 2011). Remarkably, the organic acid levels are influenced by $\mathrm{N}$ contents (Hodges 2002). Some organic acids seem to be somewhat involved in moderate (fumaric and nicotinic acids) or severe (malic acid) $\mathrm{N}$ deficiency responses. In contrast, glyceric and malonic acids, for example, seem to be involved in both conditions of $\mathrm{N}$ stress (Fig. 3). Fumaric acid is a dicarboxylic acid, intermediary in the TCA cycle, and also acts as an alternative carbon source. This acid is generated by the oxidation of succinic acid and is subsequently converted in malic acid by the enzymatic action of fumarase (Araújo et al. 2011). In some plants, like tobacco, Arabidopsis and tomato, $\mathrm{N}$ deficiency resulted in low levels of fumaric and malic acids (Ghosh et al. 1960; Scheible et al. 1997; Tschoep et al. 2009), and the same pattern was observed in this work, particularly for $0 \% \mathrm{~N}$ treatment at 3 DAT. However, malic acid accumulated in the same treatment at $7 \mathrm{DAT}$, suggesting a change in its regulation with the continuity of the $\mathrm{N}$ starvation. An explanation for such change is related to the regulation of malate biosynthesis, common mechanism observed in plants exposed to severe stresses (Dinakar et al. 2016; Salvato et al. 2019; Zhao et al. 2018). Diverse stresses promote an imbalance in energetic metabolism, requiring a higher respiration rate to cope with plant responses to this new stressful environment (Salvato et al. 2019; Zhao et al. 2018). However, the increase of respiration rate also promotes higher production of reactive oxygen species (ROS), triggering oxidative stress responses. Among those responses, an upregulation of malate biosynthesis is observed, draining part of the energy consumed by ROS and also reducing their production (Dinakar et al. 2016; Zhao et al. 2018). In that sense, changes on malate content observed at the present work point out to delicate balance between respiratory metabolism and $\mathrm{N}$ starvation and sugarcane cells and should be the focus of future studies regarding the improvement of this crop yield under stressful conditions.

Concerning carbohydrate metabolism, their polls often increase in N deficient plants (Schlüter et al. 2012; Sperdouli and Moustakas 2012). Although these treatments with absence and low availability of $\mathrm{N}$ promoted a higher accumulation of maltose, glucose and ribose derivates, it was not possible to see many other significant alterations in sugar accumulation (Fig. 4). This lack of response of most carbohydrates identified in this work suggests strong control over carbon metabolism in sugarcane cells. This fine control is expected, once carbohydrate metabolism is the core of the biosynthesis of diverse other metabolites and source of energy to the stress responses promoted by nitrogen starvation. Moreover, this strict homeostasis of carbon metabolism should be maintained as stable as possible, even if it affects other metabolic pathways, such as the degradation of macromolecules (i.e., proteins) or the biosynthesis of phenolic compounds. This stability is essential for maintaining the carbon and nitrogen balance, as discussed here and as well as other groups (Bassi et al. 2018; Dinakar et al. 2016; Salvato et al. 2019).

Putrescine (Put) and spermidine (Spd) are metabolites involved in a variety of processes in plant cells, and their accumulation levels are subjected to numerous stress conditions (Recalde et al. 2020; Spormann et al. 2020). In higher plants, the decarboxylation of Orn or Arg leads to Put formation, which is subsequently converted to Spd (Bouchereau et al. 1999). The levels of Spd were highly influenced by both $\mathrm{N}$ deficit stresses studied at this work (Fig. 5), suggesting their participation in response to $\mathrm{N}$ starvation. However, the precise roles of these metabolites in stressful conditions for sugarcane must be better understood, opening new perspectives for future studies (Moschou et al. 2008).

Using PCA, a clear separation of control and stressed groups was observed (Fig. 7a). Combining PCA data with correlation matrix analysis (Fig. 7b), it was possible to describe a more precise scenario after $\mathrm{N}$ stress treatments. In general, $\mathrm{N}$ starvation promotes positive correlation between sugars, amino acids and phenolic compounds, especially at the beginning of $\mathrm{N}$ starvation (3 DAT). In that way, this work suggests that under $\mathrm{N}$ starvation, sugarcane cells rapidly degrade proteins to improve the amount of $\mathrm{N}$ sources available, increasing the levels of free amino acids and, also, the levels of sugars and $\mathrm{N}$ compounds, derived from amino acids catabolism. Moreover, the increased amount of some phenolic compounds in cells growing under $\mathrm{N}$ deficiency support the idea of carbon sink compensation, as discussed earlier (Bassi et al. 2018; Bottcher et al. 2013; Fritz et al. 2006; Salvato et al. 2019). Therefore, a reorganization of cell metabolism to respond to this stress can be expected, showing some similar patterns of interactions among different compounds of the same metabolic classes. 
In conclusion, metabolic adaptation enables plants to cope with stressful conditions. In this work, a comprehensive exploration of sugarcane cells metabolome in response to $\mathrm{N}$ starvation after three and seven days of exposition to this stress was reported, and it was possible to identify metabolites involved with $\mathrm{N}$-deficit stress responses. For that, cell suspension as a study model was used. These results show that sugarcane cells growing under $\mathrm{N}$ deprivation can reprogram their metabolism, indicating that an adjustment for an efficiency increase might exist. In a complex system, such as the whole sugarcane plant, with high amounts of sucrose accumulation, variation in $\mathrm{N}$ supply as a fertilizer may change allocation and partition of $\mathrm{N}$ among organs in a way to guarantee carbon allocation in sucrose.

\section{AUTHORS' CONTRIBUTION}

Conceptualization: Bottcher A. and Mazzafera P.; Methodology: Bottcher A., Domingues-Jr A. P., Souza L. P., Araújo W. L., Tohge T., Fernie A. R. and Mazzafera P.; Writing - Original Draft: Bottcher A., Domingues-Jr A. P., Souza L. P. and Mazzafera P.; Writing - Review and Editing: Domingues-Jr A. P., Souza L. P. and Mazzafera P.; Funding Acquisition:Mazzafera P.; Resources: Fernie A. R.; Supervision: Mazzafera P.

\section{DATA AVAILABILITY STATEMENT}

The data will be available upon request;

\section{FUNDING}

Fundação de Amparo à Pesquisa do Estado de São Paulo

[https://doi.org/10.13039/501100001807]

Grants No. 2008/58035-6, 2018/20572-2

\section{ACKNOWLEDGMENTS}

The authors thank Laerti Reis Roque (Universidade Estadual de Campinas) and Ilse Balbo (Max-Planck-Institut für Molekulare Pflanzenphysiologie) for technical assistance.

\section{REFERENCES}

El-Kader, E. M. A., Serag, A., Aref, M. S., Ewais, E. E. A. and Farag, M. A. (2019). Metabolomics reveals ionones upregulation in MeJA elicited Cinnamomum camphora (camphor tree) cell culture. Plant Cell, Tissue and Organ Culture, 137, 309-318. https://doi.org/10.1007/ s11240-019-01572-z

Abreu, L. G. F., Grassi, M. C. B., Carvalho, L. M., Silva, J. J. B., Oliveira, J. V. C., Bressiani, J. A. and Pereira, G. A. G. (2020). Energy cane vs sugarcane: Watching the race in plant development. Industrial Crops and Products, 156, 112868. https://doi.org/10.1016/j. indcrop.2020.112868

Araújo, W. L., Nunes-Nesi, A. and Fernie, A. R. (2011) Fumarate: Multiple functions of a simple metabolite. Phytochemistry, 72, 838-843. https://doi.org/10.1016/j.phytochem.2011.02.028 
Bassi, D., Menossi, M. and Mattiello, L. (2018). Nitrogen supply influences photosynthesis establishment along the sugarcane leaf. Scientific Reports, 8, 2327. https://doi.org/10.1038/s41598-018-20653-1

Bottcher, A., Cesarino, I., Santos, A. B., Vicentini, R., Mayer, J. L. S., Vanholme, R., Morreel, K., Goeminne, G., Moura, J. C. M. S., Nobile, P. M., Carmello-Guerreiro, S. M., Anjos, I. A., Creste, W. B., Boerjan, W., Landell, M. G. A. and Mazzafera. P. (2013). Lignification in sugarcane: Biochemical characterization, gene discovery, and expression analysis in two genotypes contrasting for lignin content. Plant Physiology, 163, 1539-1557. https://doi.org/10.1104/pp.113.225250

Bouchereau, A., Aziz, A., Larher, F. and Martin-Tanguy, J. (1999). Polyamines and environmental challenges: recent development. Plant Science, 140, 103-125. https://doi.org/10.1016/S0168-9452(98)00218-0

Byrt, C. S., Grof, C. P. L. and Furbank, R. T. (2011). C 4 Plants as biofuel feedstocks: optimising biomass production and feedstock quality from a lignocellulosic perspective. Journal of Integrative Plant Biology, 53, 120-135. https://doi.org/10.1111/j.1744-7909.2010.01023.x

Calderan-Rodrigues, M. J., Dantas, L. L. B., Gianotto, A. C. and Caldana, C. (2021). Applying Molecular phenotyping tools to explore sugarcane carbon potential. Frontiers in Plant Science, 12, 637166. https://doi.org/10.3389/fpls.2021.637166

Cesarino, I., Araújo, P., Paes Leme, A. F., Creste S. and Mazzafera P. (2013). Suspension cell culture as a tool for the characterization of class III peroxidases in sugarcane. Plant Physiology and Biochemistry, 62, 1-10. https://doi.org/10.1016/j.plaphy.2012.10.015

Coder, D. M. (2001). Assessment of cell viability. In Current protocols in cytometry (pp. 9.2.1-9.2.14). John Wiley \& Sons. https://doi. org/10.1002/0471142956.cy0902s15

Dias, M. O. S, Junqueira, T. L., Cavalett, O., Cunha, M. P., Jesus, C. D. F., Rossell, C. E. V., Maciel Filho, R. and Bonomi, A. (2012). Integrated versus stand-alone second generation ethanol production from sugarcane bagasse and trash. Bioresource Technology, $103,152-161$. https://doi.org/10.1016/j.biortech.2011.09.120

Diaz, C., Saliba-Colombani, V., Loudet, O., Belluomo, P., Moreau, L., Daniel-Vedele, F., Morot-Gaudry, J.-F. and Masclaux-Daubresse, C. (2006). Leaf yellowing and anthocyanin accumulation are two genetically independent strategies in response to nitrogen limitation in Arabidopsis thaliana. Plant and Cell Physiology, 47, 74-83. https://doi.org/10.1093/pcp/pci225

Dinakar, C., Vishwakarma, A., Raghavendra, A. S. and Padmasree, K. (2016). Alternative oxidase pathway optimizes photosynthesis during osmotic and temperature stress by regulating cellular ROS, malate valve and antioxidative systems. Frontiers in Plant Science, 7, 68. https://doi.org/10.3389/fpls.2016.00068

Ferreira, D. A., Martins, M. C. M., Cheavegatti-Gianotto, A., Carneiro, M. S., Amadeu, R. R., Aricetti, J. A., Wolf, L. D., Hoffmann, H. P., Abreu, L. G. F. and Caldana, C. (2018). Metabolite profiles of sugarcane culm reveal the relationship among metabolism and axillary bud outgrowth in genetically related sugarcane commercial cultivars. Frontiers in Plant Science, 9, 857. https://doi.org/10.3389/fpls.2018.00857

Fritz, C., Palacios-Rojas, N., Feil, R. and Stitt, M. (2006). Regulation of secondary metabolism by the carbon-nitrogen status in tobacco: nitrate inhibits large sectors of phenylpropanoid metabolism. The Plant Journal, 46, 533-548. https://doi.org/10.1111/j.1365-313X.2006.02715.X

Galili, S., Amir, R. and Galili G. (2008). Genetic engineering of amino acid metabolism in plants. Advances in Plant Biochemistry and Molecular Biology, 1. 49-80. https://doi.org/10.1016/S1755-0408(07)01003-X

Ghosh, S., Blumenthal, H. J., Davidson, E. and Roseman., S. (1960). Glucosamine metabolism: V. enzymatic synthesis of glucosamine 6-phosphate. The Journal of Biological Chemistry, 235, 1265-1273. https://doi.org/10.1016/S0021-9258(18)69397-4

Guo, S.-W., Zhou, Y., Gao, Y.-X., Li, Y. and Shen, Q.-R. (2007). New insights into the nitrogen form effect on photosynthesis and photorespiration. Pedosphere, 17, 601-610. https://doi.org/10.1016/S1002-0160(07)60071-X

Hodges, M. (2002). Enzyme redundancy and the importance of 2 oxoglutarate in plant ammonium assimilation. Journal of Experimental Botany, 53, 905-916. https://doi.org/10.1093/jexbot/53.370.905 
Landell, M. G. A., Pinto, L. R., Creste, S., Xavier, M. A., Anjos, I. A., Vasconcelos, A. C. M., Bidóia, M. A. P., Silva, D. N. and Silva, M. A.(2005). 4. Seleção de novas variedades de cana-de-açúcar e seu manejo de produção [Encarte de Informações Agronômicas 110]. Piracicaba: POTAFOS.

Lea, P. J. and Miflin, B. J. (2011). Nitrogen assimilation and its relevance to crop improvement. In C. H. Foyer and H. Zhang (Org.), Annual Plant Reviews book series, Volume 42: Nitrogen Metabolism in Plants in the Post genomic Era (pp. 1-40). Hoboken: Blackwell. https:// doi.org/10.1002/9781119312994.apr0448

Lisec, J., Schauer, N., Kopka, J., Willmitzer, L. and Fernie, A. R. (2006). Gas chromatography mass spectrometry-based metabolite profiling in plants. Nature Protocols, 1, 387-396. https://doi.org/10.1038/nprot.2006.59

Llerena, J. P. P., Figueiredo, R., Brito, M. S., Kiyota, E., Mayer, J. L. S., Araújo, P., Schimpl, F. C., Dama, M., Pauly, M. and Mazzafera, P. (2019). Deposition of lignin in four species of Saccharum. Scientific Reports, 9, 5877. https://doi.org/10.1038/s41598-019-42350-3

Moschou, P. N., Paschalidis, K. A. and Roubelakis-Angelakis, K. A. (2008). Plant polyamine catabolism: The state of the art. Plant Signaling \& Behavior, 3, 1061-1066. https://doi.org/10.4161/psb.3.12.7172

Murashige, T. and Skoog, F. (1962). A Revised Medium for Rapid Growth and Bio Assays with Tobacco Tissue Cultures. Physiologia Plantarum, 15, 473-497. https://doi.org/10.1111/j.1399-3054.1962.tb08052.x

Noctor, G., Novitskaya, L., Lea, P. J. and Foyer, C. H. (2002). Co ordination of leaf minor amino acid contents in crop species: significance and interpretation. Journal of Experimental Botany, 53, 939-945. https://doi.org/10.1093/jexbot/53.370.939

Patade, V. Y., Bhargava, S. and Suprasanna, P. (2012). Effects of NaCl and iso-osmotic PEG stress on growth, osmolytes accumulation and antioxidant defense in cultured sugarcane cells. Plant Cell, Tissue and Organ Culture, 108, 279-286. https://doi.org/10.1007/ s11240-011-0041-5

Peng, M., Bi, Y.-M., Zhu, T. and Rothstein S. J. (2007). Genome-wide analysis of Arabidopsis responsive transcriptome to nitrogen limitation and its regulation by the ubiquitin ligase gene NLA. Plant Molecular Biology, 65, 775-797. https://doi.org/10.1007/s11103-007-9241-0

Portz, G., Molin, J. P. and Jasper, J. (2012). Active crop sensor to detect variability of nitrogen supply and biomass on sugarcane fields. Precision Agriculture, 13, 33-44. https://doi.org/10.1007/s11119-011-9243-4

Recalde, L., Mansur, N. M. G., Cabrera, A. V., Matayoshi, C. L., Gallego, S. M., Groppa, M. D. and Benavides, M. P. (2020). Unravelling ties in the nitrogen network: Polyamines and nitric oxide emerging as essential players in signalling roadway. Annals of Applied Biology, 178, 192-208. https://doi.org/10.1111/aab.12642

Robinson, N., Brackin, R., Vinall, K., Soper, F., Holst, J., Gamage, H., Paungfoo-Lonhienne, C., Rennenberg, H., Lakshmanan, P. and Schmidt, S. (2011). Nitrate paradigm does not hold up for sugarcane. PLoS ONE, 6, e19045. https://doi.org/10.1371/journal.pone.0019045 Salvato, F., Loziuk, P., Kiyota, E., Daneluzzi, G. S., Araujo, P., Muddiman, D. C and Mazzafera, P. (2019). Label free quantitative proteomics of enriched nuclei from sugarcane (Saccharum ssp) stems in response to drought stress. Proteomics, 19, 1900004. https://doi.org/10.1002/ pmic.201900004

Schachtman, D. P. and Shin, R. (2007). Nutrient sensing and signaling: NPKS. Annual Review of Plant Biology, 58, 47-69. https://doi. org/10.1146/annurev.arplant.58.032806.103750

Scheible, W.-R., González-Fontes, A., Lauerer, M., Müller-Röber, B., Caboche, M. and Stitt, M. (1997). Nitrate acts as a signal to induce organic acid metabolism and repress starch metabolism in tobacco. The Plant Cell, 9, 783-798. https://doi.org/10.2307/3870432

Schlüter, U., Mascher, M., Colmsee, C., Scholz, U., Bräutigam, A., Fahnenstich, H. and Sonnewald, U. (2012). Maize source leaf adaptation to nitrogen deficiency affects not only nitrogen and carbon metabolism but also control of phosphate homeostasis. Plant Physiology, 160, 1384-1406. https://doi.org/10.1104/pp.112.204420

Soares, C., Carvalho, M. E. A., Azevedo, R. A. and Fidalgo, F. (2019). Plants facing oxidative challenges-A little help from the antioxidant networks. Environmental and Experimental Botany, 161, 4-25. https://doi.org/10.1016/j.envexpbot.2018.12.009 
Sperdouli, I. and Moustakas, M. (2012). Interaction of proline, sugars, and anthocyanins during photosynthetic acclimation of Arabidopsis thaliana to drought stress. Journal of Plant Physiology, 169, 577-585. https://doi.org/10.1016/j.jplph.2011.12.015

Spormann, S., Soares, C., Teixeira, J. and Fidalgo, F. (2020). Polyamines as key regulatory players in plants under metal stress-A way for an enhanced tolerance. Annals of Applied Biology, 178, 209-226. https://doi.org/10.1111/aab.12660

Stitt, M. (1999). Nitrate regulation of metabolism and growth. Current Opinion in Plant Biology, 2, 178-186. https://doi.org/10.1016/ S1369-5266(99)80033-8

Thorburn, P. J., Meier, E. A. and Probert, M. E. (2005). Modelling nitrogen dynamics in sugarcane systems: Recent advances and applications. Field Crops Research, 92, 337-351. https://doi.org/10.1016/j.fcr.2005.01.016

Tohge, T. and Fernie, A. R. (2010). Combining genetic diversity, informatics and metabolomics to facilitate annotation of plant gene function. Nature Protocols, 5, 1210-1227. https://doi.org/10.1038/nprot.2010.82

Tschoep, H., Gibon, Y., Carillo, P., Armengaud, P., Szecowka, M., Nunes-Nesi, A., Fernie, A. R., Koehl, K. and Stitt, M. (2009). Adjustment of growth and central metabolism to a mild but sustained nitrogen limitation in Arabidopsis. Plant, Cell \& Environment, 32, $300-318$. https://doi.org/10.1111/j.1365-3040.2008.01921.x

Wang, H.-Z. and Dixon, R. A. (2012). On-off switches for secondary cell wall biosynthesis. Molecular Plant, 5, 297-303. https://doi. org/10.1093/mp/ssr098

Zhao, Y., Luo, L., Xu, J., Xin, P., Guo, H., Wu, J., Bai, L., Wang, G., Chu, J., Zuo, J., Yu, H., Huang, X. and Li, J. (2018). Malate transported from chloroplast to mitochondrion triggers production of ROS and PCD in Arabidopsis thaliana. Cell Research, 28, 448-461. https:// doi.org/10.1038/s41422-018-0024-8

Zhong, R., Lee, C. and Ye, Z.-H. (2010). Evolutionary conservation of the transcriptional network regulating secondary cell wall biosynthesis. Trends in Plant Science, 15, 625-632. https://doi.org/10.1016/j.tplants.2010.08.007 